\title{
0 texto do material planejado de uma formação e-learning em modelagem matemática tematizando bullying
}

\author{
Larissa Borges de Souza Lima \\ Ana Virginia de Almeida Luna
}

\begin{abstract}
Resumo: Esta pesquisa teve como propósito identificar os textos do discurso instrucional de modelagem matemática, tematizando o bullying, dos materiais planejados pelos formadores, que foram operados na relação pedagógica entre formadores e professores da educação básica, que participaram de uma formação e-learning. O estudo foi desenvolvido com base em dados do projeto de pesquisa interinstitucional, financiado pelo CNPq, Modelagem matemática na educação básica: efeitos de um ensino problematizador. A partir da análise documental do planejamento da formação foram desenvolvidas categorias de análise, em uma abordagem qualitativa, por meio do modelo sociológico da linguagem de descrição proposta por Basil Bernstein. Os resultados identificam a importância da modelagem e a experiência no espaço remoto, bem como, a modelagem matemática como forma de reconhecer 0 fenômeno bullying pelos professores em formação.
\end{abstract}

Palavras-chave: Discurso instrucional de modelagem. Formação de professor. Educação básica.

Larissa Borges de Souza Lima Mestre em Educação pela Universidade Estadual de Feira de Santana (UEFS). Coordenadora Pedagógica dos Anos Finais do Ensino Fundamental do Colégio Despertar, Feira de Santana, Bahia, Brasil.

http://orcid.org/0000-0003-4824-4023

$\bowtie$ limaborgeslarissa@gmail.com

Ana Virginia de Almeida Luna Doutora em Ensino, Filosofia e História das Ciências pela Universidade Federal da Bahia (UFBA) e Universidade Estadual de Feira de Santana (UEFS), Professora Adjunta (UEFS), Feira de Santana, Bahia Brasil.

http://orcid.org/0000-0002-0106-487X $\triangle$ avaluna@uefs.br

Recebido em 16/05/2021 Aceito em 30/06/2021 Publicado em 21/08/2021

\section{The text of the planned material of an e-learning training in mathematical modeling thematizing bullying}

Abstract: This research aimed to identify the texts of the instructional discourse of mathematical modeling, thematizing bullying, from the materials planned by the trainers, which were operated in the pedagogical relationship between trainers and teachers of basic education, who participated in an e-learning training. The study was developed based on data from the inter-institutional research project, funded by $\mathrm{CNPq}$, Mathematical modeling in basic education: effects of problem-solving teaching. From the documental analysis of training planning, analysis categories were developed, in a qualitative approach, through the sociological model of the language of description proposed by Basil Bernstein. The results identify the importance of modeling and experience in remote space, as well as mathematical modeling as a way to recognize the bullying phenomenon by teachers in training.

Keywords: Modeling instructional discourse. Teacher training. Basic education.

\section{El texto del material planificado de una formación e-learning en modelización matemática temática del bullying escolar}

Resumen: Esta investigación tuvo como objetivo identificar los textos del discurso instruccional de modelado matemático, tematizando el bullying, a partir de los materiales planificados por los formadores, los cuales fueron operados en la relación pedagógica entre formadores y docentes de educación básica, quienes participaron e-learning. El estudio se desarrolló a partir de datos del proyecto de investigación interinstitucional, financiado por el CNPq, Modelización matemática en educación básica: efectos de la enseñanza resolutiva. A partir del análisis documental de la planificación de la formación, se desarrollaron categorías de análisis, en un enfoque cualitativo, a través del modelo sociológico del lenguaje de descripción propuesto por Basil Bernstein. Los resultados identifican la importancia de la modelización y la 
experiencia en el espacio remoto, así como la modelización matemática como una forma de reconocer el fenómeno del bullying por parte de los profesores en formación.

Palabras clave: Modelación del discurso instruccional. Formación de profesores. Educación básica.

\section{Introdução}

O foco de nossa pesquisa centra-se em identificar os textos do discurso instrucional de modelagem matemática, tematizando o bullying, dos materiais planejados pelos formadores, que foram operados na relação pedagógica entre formadores e professores da educação básica, que participaram de uma formação e-learning. Os textos, aqui, são entendidos como qualquer forma de comunicação escrita, falada ou gestos, expressões faciais, registros escritos, entre outros (BERNSTEIN, 2017).

A nossa opção por este espaço colaborativo e-learning ${ }^{1}$ se deu pelo contexto atual que estamos vivendo no Brasil - a pandemia de COVID-19. Assim sendo, a implementação da modalidade on-line, no processo de formação, ocorreu dentro de um contexto emergencial, por compreendermos a importância e a relevância desse momento formativo para professores que estão sendo, também, desafiados a aprender novas interfaces para garantir as aprendizagens dos estudantes.

O presente estudo foi desenvolvido a partir de uma pesquisa interinstitucional, financiada pelo Conselho Nacional de Desenvolvimento Científico e Tecnológico (CNPq), por meio do CONSEPE 049/2020, intitulada Modelagem matemática na educação básica: efeitos de um ensino problematizador, a qual envolveu três instituições de ensino superior estaduais da Bahia. Para a pesquisa que estamos apresentando, neste artigo, a trajetória metodológica teve como propósito atender o objetivo do estudo que visou identificar os textos do discurso instrucional de modelagem matemática², tematizando o bullying, dos materiais planejados pelos formadores. Estes formadores eram membros de três núcleos de pesquisa da Sociedade Brasileira de Educação Matemática Regional Bahia, SBEM-BA, sediados em universidades baianas, a saber, Vitória da Conquista (UESB), Amargosa (UFRB) e Feira de Santana (UEFS). Tais textos dos materiais foram operados na relação pedagógica entre formadores e professores da educação básica, que

\footnotetext{
${ }^{1}$ Nichols (2008) define e-learning como processos pedagógicos por meio do uso da tecnologia digital. Segundo 0 autor e-learning é uma combinação de e-(eletrônico) e aprendizagem, mas sempre dirigido pelas intervenções pedagógicas.

2 Nesta pesquisa, Modelagem Matemática (modelagem) é entendida como um ambiente de aprendizagem em que estudantes são convidados a investigar, utilizando a matemática, em situações com referência na realidade (BARBOSA, 2001).
} 
participaram da formação e-learning. Os participantes foram 47 professores de matemática da educação básica de diferentes escolas públicas dessas três cidades.,

Para tanto, realizamos a pesquisa em uma abordagem qualitativa, por meio da linguagem de descrição, modelo metodológico, desenvolvido por Bernstein (2017), cujo propósito é favorecer uma relação dialética entre os conceitos constituídos por uma teoria e os dados empíricos a serem analisados.

Os resultados da pesquisa nos auxiliam a entender melhor os processos de transformações dos textos dos participantes. Neste caso, todos os envolvidos no espaço de formação, agregaram novos conhecimentos, novos textos, a partir do planejamento desenvolvido para formação, partindo da interação dos sujeitos no ambiente formativo e de elementos de uma prática interativa.

Nas próximas seções apresentamos como se deu a formação e-learning e o que compreendemos sobre prática pedagógica. Bem como, entender a modelagem, com um ambiente de aprendizagem para o ensino da matemática e de como a interação com temas interdisciplinares, como o bullying, favorecem a produção de textos legítimos por professores, consequentemente a aprendizagem dos estudantes. Por fim, dialogamos, por meio da análise de dados, sobre a importância do ambiente formativo, em um espaço e-learning.

\section{A formação e-learning de professores e a prática pedagógica}

Ao dialogar sobre prática pedagógica, compreendemos que ela não está centrada na figura do professor e sim a um contexto social pelo qual se realiza a reprodução e a produção de culturas (BERNSTEIN, 2017). A prática pedagógica não se refere, conforme o autor, a um sujeito, dessa forma, não nos cabe dizer que a prática pedagógica é do professor, e sim a uma relação social que se estabelece em diferentes contextos. Assim sendo, não existe prática pedagógica apenas em sala de aula, professor/aluno, mas em toda relação social de poder, a saber: médico/paciente; formador/ professores; psiquiatra/paciente; arquitetos/pedreiros etc.; e está necessariamente determinada pelas relações de poder que se dá no interior dela e que determinam as distintas formas de aquisição do conhecimento.

Segundo Bernstein (2017), por meio dessas relações sociais há a seleção sobre os princípios e os focos da comunicação, como, por exemplo, o que se pode dizer e como se pode dizer, por sua vez, criando regras de interpretação, relação e identidade para seus falantes. Em 
outras palavras, as relações sociais agem seletivamente sobre as escolhas léxicas e sintáticas, sobre a metáfora e o simbolismo.

Ao considerarmos, por exemplo, a sala de aula como uma prática pedagógica, é por meio do discurso pedagógico que os diferentes conteúdos matemáticos são socializados, a partir de diversos ambientes de aprendizagem ${ }^{3}$ diferentes conteúdos são aprendidos, mediante a realização de uma comunicação especializada.

A prática pedagógica, que no caso dessa pesquisa é a formação de professores, se concretiza por meio da socialização e interação de saberes e conhecimentos acerca da modelagem tematizando o bullying, mas também de construir outros. A opção pelo formato elearning, em um momento em que a sociedade se encontra em distanciamento social, por conta da pandemia do coronavírus, se efetiva por acreditarmos que uma formação se materializa com 0 trabalho do formador de intervir, por meio de práticas pedagógicas, para ampliação dos textos dos professores; e o trabalho dos professores de refletir sobre os saberes sistematizados, nesse espaço. Nesse sentindo, o que menos importa são as paredes que se configuram como sala, já que o processo pelo qual se efetiva essa interação também pode se dar pelo formato e-learning.

Optamos por conduzir todo o processo formativo baseado na modalidade e-learning (Learning Management System), uma das possibilidades de formação on-line, pois concordamos com Bose (2003) e Nichhols (2008) de que este modelo envolve a utilização de internet e outros meios tecnológicos para promover e apoiar processos de ensino e aprendizagem.

Diferentemente da formação à distância, no formato EAD, essa modalidade registra cada dado de participação de professor, por mais simples que possa parecer, desde que tenha aberto uma apresentação, até que tenha respondido um questionário on-line, por meio de suas respostas a algumas perguntas em um fórum. Tudo fica registrado de forma automática na plataforma, assim também, a interação e contato são permanentes, não quando há apenas a postagem de materiais, característico do formado EAD, mas sim por múltiplas possibilidades de interações, como mensagens, chats, encontros ao vivo, entre outros (FREITAS, 2009).

A modalidade e-learning, para que se efetive, de acordo com Freitas (2009), não pode se basear em um modelo aprendizagem expositivo, e sim em um modelo que privilegie o diálogo, 0 encorajamento entre o grupo, orientados pelo formador, por meio do estímulo à discussão entre os participantes, a partir de variadas tecnologias.

\footnotetext{
${ }^{3}$ Ambiente de aprendizagem são as condições nas quais os alunos são estimulados a desenvolverem determinadas atividades (SKOVSMOSE, 2008).
} 
Concordamos com Pultoo e Oojorah (2020), por meio de tradução nossa, de que as circunstâncias do Coronavírus estão fazendo com que Ministério de Educação, escolas e universidades, em todo mundo, se mobilizem para possibilitar o aprendizado. Para os autores, a utilização da tecnologia da educação pode ser realizada de diferentes maneiras comunicativas, de forma síncrona ou assíncrona.

As tecnologias que são utilizadas de forma síncrona exigem que todos os envolvidos participem juntos, em simultâneo, embora não seja no mesmo local. São exemplos as tecnologias utilizadas para videoconferência, conversas e bate-papos, permitindo interação, questionamentos e compartilhamento de ideias, como a utilizada na formação - Google Meet. Vale salientar que, para elas serem eficazes podem ser incluídos recursos. As tecnologias que possibilitam a interação assíncrona permitem que os participantes acessem materiais ou se comuniquem em diferentes momentos, como exemplos, mídias gravadas, vídeos, YouTube, fóruns de discussões.

Na perspectiva de uma formação em que o diálogo e a interação se efetivem, o planejamento das tarefas foi realizado com o propósito de engajar os professores em formação com a modelagem. Para tanto, foram utilizadas tecnologias das diferentes maneiras socializadas por Pultoo e Oojorah (2020).

Por meio da formação na modalidade e-learning, assim como pode acontecer no formato presencial, o discurso é modificado (por meio de seleção, simplificação, condensação e reelaboração) e relacionado com outros discursos e depois é relocado. Nesse processo, o discurso real (original) passa por uma transformação, criando um discurso imaginário ou virtual, como, por exemplo, de uma formação de professores. Nesse sentido, o discurso não é mais o mesmo, já que se apropria de outros discursos.

A produção de textos dos professores em um contexto de formação envolve a seleção, sequenciamento, ritmo e critérios dos conteúdos que devem ser transmitidos aos alunos, os quais constituem o discurso instrucional (BERNSTEIN, 2017).

O deslocamento do discurso de seu lugar de origem para outro provoca um efeito de transformação de um discurso original para um discurso virtual. Na presente pesquisa entendemos o discurso de modelagem como um discurso instrucional da matemática, ou seja, um discurso especializado da matemática a ser transmitido na prática pedagógica.

Neste estudo o nosso olhar será na prática pedagógica, referindo-se aos textos no processo formativo, considerando a relação formador(a) e professor(a). Assim sendo, essa pesquisa apresenta uma comparação do texto inicial, com o novo texto que circula na formação. 
Com isso, o texto, por certo, sofre mudanças em relação ao texto inicial. De fato, trata-se de textos diferentes em movimento, o texto inicial no processo formativo são os que circulam na primeira etapa da formação sobre modelagem, mediante os propósitos de cada encontro, e o texto final, será deslocado desta primeira etapa, para ser circulado durante a produção do planejamento final e a realização da atividade produzida.

Na próxima seção abordaremos sobre a concepção de modelagem e da importância de se tematizar o bullying.

\section{A modelagem matemática tematizando o bullying}

Existem muitos ambientes de aprendizagens que têm como finalidade encorajar os estudantes a se tornarem conscientes em relação ao papel da matemática em sociedade. Segundo Civiero (2016), todo espaço escolar em que há interação entre professor e estudante constitui um ambiente de aprendizagem. Um desses ambientes é o da modelagem, cuja função é possibilitar a aproximação dos alunos estudantes de problemas da realidade, favorecendo a interação desses, com diversos temas sociais, de forma a contribuir para uma análise reflexiva e crítica acerca de situações do cotidiano.

Ao considerarmos o ambiente de modelagem, em uma perspectiva sociocrítica, conforme Barbosa $(2003,2006 a, 2006 b)$, com foco na natureza e seus usos na sociedade de forma enviesada, a abordagem matemática dada às problematizações, às situações-problema reais, em modelagem, se constitui por meio da produção de textos legítimos ${ }^{4}$ na prática pedagógica. Os textos produzidos possibilitam a realização do uso da matemática escolar para compreender o que está acontecendo a sua volta, matematizando para resolver as diversas situações no contexto escolhido, podendo assim, dialogar sobre temática da moral, como exemplo, o bullying.

O bullying é uma forma de violência peculiar, complexa, a ponto de existir uma lei antibullying já incorporada à Lei de Diretrizes e Bases (LDB), como tema importante a ser incorporados nos currículos das escolas.

Segundo Tognetta (2015), não se pode mais fugir de uma responsabilidade que é dos educadores, já que diariamente crianças e adolescentes sofrem, praticam ou presenciam agressões dessa natureza, a maioria das vezes velada, no ambiente escolar. Por essa razão, é

\footnotetext{
$4 \mathrm{O}$ texto é compreendido como legítimo quando é reconhecido por quem o comunica como específico daquela comunicação (BORTOLOTI; PEROVANO, 2018).
} 
preciso que os professores compreendam as características do fenômeno para saber intervir de forma que seus alunos superem seus problemas, por meio da socialização dos sentimentos.

No Brasil, grande parte dos professores não teve e continua não tendo em sua formação a oportunidade de estudar os aspectos da convivência como um conteúdo tão importante quanto à metodologia da matemática, das ciências etc. Poucos aprenderam como lidar com as agressões, ou mesmo como ajudar seus alunos a resolver conflitos de forma assertiva. Poucas também são as possibilidades que nossos professores têm de discutir essas questões, ainda que sejam exatamente essas suas maiores dificuldades no cotidiano escolar (TOGNETTA, 2015, p. 11).

Os professores pouco sabem como intervir em situações de bullying, até porque muitos 0 confundem como brincadeira da idade e que, por conseguinte, resolverão sozinhos. Por falta de formação, o que se acredita ser mais importante são os conteúdos conceituais e não os conteúdos sociais.

O desconhecimento em relação ao fenômeno bullying, inclusive sendo tratado por muitas ciências como preconceito, é uma forma de violência com especificidades e uma dinâmica profunda que exige compreensão de toda a sua natureza, como nos dizem as pesquisas de Avilés (2006, 2013); Tognetta (2010, 2015); Tognetta e Vinha (2009).

Tognetta, Vinha e Avilés (2014) ressaltam que em suas pesquisas ainda se surpreendem com professores que não acreditam que exista um problema tão escondido e que passe de forma tão despercebida a seus olhos. Além disso, de que algumas características sejam observadas como simples brincadeiras e não como indicativos de bullying.

Os estudos investigativos de Díaz-Aguado (2015), em contexto educacional, revelam que a aprendizagem cooperativa pode ser desenvolvida em qualquer matéria, em todos os níveis educativos. Inclusive, a aprendizagem cooperativa, em sua pesquisa, começou a ser desenvolvida em matemática e linguagem. A pesquisadora conseguiu concluir que a aprendizagem cooperativa ocorre de forma mais efetiva quando as atividades são bem estruturadas.

A partir de uma atividade de modelagem, tematizando o bullying, pode-se abrir espaço, na escola, para o desenvolvimento de um "Plano de Convivência, fazendo com que os estudantes se tornem protagonistas da educação, tornando-se parte da solução e não do problema" (AVILÉS, 2018, p. 30).

O que se evidencia em uma atividade de modelagem é que se tem um problema a resolver, de natureza real e exige matematizações, por meio de estratégias próprias, algoritmos, gráficos, bem como, validação das respostas e, mais importante, das diferentes respostas que se têm para manejar situações de convivência na escola para prevenção do bullying. Dessa forma, 
no processo de reflexão sobre aspecto da realidade, são selecionados os argumentos importantes para formalização (modelo matemático) que contemple matematizar tais argumentos.

Evidentemente, a atividade de modelagem não se configura como uma atividade comum a ser desenvolvida em sala de aula, tanto pelos professores, quanto para os estudantes que estão inseridos em práticas pedagógicas em que o texto é produzido pelo professor. Porém, ao ser iniciada há uma boa percepção dos efeitos reflexivos acerca do objeto tematizado, por toda comunidade escolar.

Barbosa (2001) apresentou a noção de "casos" para organizar atividade de modelagem, com diferentes divisões de responsabilidade entre professor e estudantes, como fica evidenciado no Quadro 1.

Quadro 1: Os casos de Modelagem

\begin{tabular}{|l|l|l|l|}
\cline { 2 - 4 } \multicolumn{1}{c|}{} & \multicolumn{1}{c|}{ Caso 1 } & \multicolumn{1}{c|}{ Caso 2 } & \multicolumn{1}{c|}{ Caso 3 } \\
\hline Elaboração do problema & Professor & Professor & Professor/alunos \\
\hline Coleta de dados & Professor & Professor/alunos & Professor/alunos \\
\hline Resolução & Professor/alunos & Professor/alunos & Professor/alunos \\
\hline
\end{tabular}

Fonte: Barbosa (2001).

O que Barbosa (2001; 2009) chamou caso 1, é quando o professor apresenta a situaçãoproblema para os estudantes, bem como os dados qualitativos e quantitativos, cabendo aos estudantes resolver a situação. Neste caso, a atividade de modelagem é mais previsível para 0 professor, já que ele conhece os dados e a situação-problema, mesmo as resoluções das situações serem imprevisíveis. O papel do professor é mediar a produção de texto dos estudantes.

Ainda segundo o autor, o caso 2 é quando o professor elabora o problema para os estudantes, porém não disponibiliza os dados qualitativos e quantitativos, fazendo com que os estudantes busquem por esses dados sobre a situação-problema. Já no caso 3, de natureza mais aberta, é dada aos estudantes a responsabilidade de formular o problema a ser resolvido, coletar as informações e solucionar o problema.

A integração curricular da modelagem, a partir da identificação de sua relevância para os estudantes, se dá por meio das ações realizadas por professores. Para isso, é preciso focar lentes no processo de formação docente, para que o professor tenha repertório para sua materialização em sala de aula (LIMA; LUNA, 2019).

Abordaremos, a seguir, a trajetória metodológica e o contexto em que foi construída a pesquisa. 


\section{Trajetória metodológica e contexto}

A escolha pela pesquisa qualitativa se justifica por conta de os pesquisadores qualitativos enfatizarem a natureza repleta de valores de investigação, buscarem soluções para as questões que realçam o modo como a experiência social é criada e adquire significado (BOGDAN; BIKLEN, 2003). Seguindo esse olhar, buscamos identificar os textos do discurso instrucional de modelagem matemática, tematizando o bullying, dos materiais planejados pelos formadores, operados na relação pedagógica entre formadores e professores da educação básica, que participaram de uma formação e-learning.

Esta pesquisa foi interinstitucional, envolvendo três núcleos de pesquisa da Sociedade Brasileira de Educação Matemática Regional Bahia, SBEM-BA, sediada em universidades baianas, a saber, Vitória da Conquista (UESB), Amargosa (UFRB) e Feira de Santana (UEFS), com o grupo de pesquisa Núcleo de Estudos em Educação Matemática de Feira de Santana, NEEMFS, o qual sediou a formação. Esta formação envolveu 47 professores de matemática da educação básica de diferentes escolas públicas, dessas três cidades, que tiverem algum tipo de interesse em participar de uma formação colaborativa em modelagem.

A natureza qualitativa da pesquisa, conforme a perspectiva de Denzin e Lincoln (2005) tem relação com as qualidades das entidades e todo o processo que não são mensurados. Assim sendo, os pesquisadores analisam e ressaltam "a natureza socialmente construída da realidade" (p. 20). Concordamos com os autores de que, no espaço formativo, em que os professores de matemática reconhecem os textos acerca de modelagem e bullying, será a fonte principal dos dados, visto que os pesquisadores qualitativos estudam seus objetos de pesquisas no lócus, compreendendo o fenômeno em termos do significado que as pessoas atribuem aos mesmos (DENZIN; LINCOLN, 2005).

Nesse sentindo, ao considerarmos o nosso contexto, a formação de professores em modelagem, com base no modelo de investigação sociológica de Bernstein (2000), linguagem de descrição que, segundo o mesmo, define-se como um diálogo entre os conceitos constituídos por uma teoria e os dados empíricos a serem analisados, a partir de dois tipos de linguagem: a interna e a externa, a saber: linguagem interna é constituída por uma teoria ou por um conjunto de teorias; e a linguagem externa ocorre por meio de proposições e modelos derivados da linguagem interna de descrição, como, por exemplo, o desenvolvimento das categorias de análise.

No percurso da pesquisa, o investigador reconhece, começa a controlar os processos de evolução da teoria, nesta pesquisa os estudos à luz da teoria de Basil Bernstein e a revisão de 
literature de formação em modelagem matemática e bullying, assim como do campo de investigação, o espaço formativo, tendo os seus conceitos utilizados para a construção de modelos teóricos e vice-versa (BERNSTEIN, 2000).

Foi utilizada, como instrumento de coleta dos dados, a observação e a análise documental, que constitui uma técnica importante na pesquisa qualitativa, seja complementando informações obtidas por outras técnicas, seja desvelando aspectos novos de um tema ou problema (LÜDKE e ANDRÉ, 1986). A partir dela, foi descrito que textos dos discursos instrucionais foram encontrados sobre modelagem, em diferentes materiais, em uma formação colaborativa e-learning de modelagem matemática. $\mathrm{O}$ ambiente da formação ocorreu na plataforma Google Meet.

\section{Análise e discussão dos dados}

$\mathrm{Na}$ análise dos resultados, buscou-se identificar os textos do discurso instrucional de modelagem matemática, tematizando o bullying, dos materiais planejados pelos formadores, que foram operados na relação pedagógica entre formadores e professores da educação básica, que participaram de uma formação e-learning. As atividades foram desenvolvidas remotamente, por meio de encontros individuais e/ou em grupos, utilizando-se ferramentas digitais.

Os professores que participaram desse modelo formativo puderam se cadastrar em uma sala de aula, por meio de uma plataforma digital disponível para dispositivos eletrônicos, o Classroom. Com a interface Google Meet, puderam participar dos encontros on-line com todos os participantes. Segue um recorte do planejamento da formação, que servirá para nossa análise.

Quadro 2: Recorte do Planejamento da Formação Modelagem Matemática relacionada ao bullying na educação básicas

\begin{tabular}{|c|c|c|}
\hline \multirow[b]{2}{*}{ ENCONTROS } & \multicolumn{2}{|r|}{ DESCRIÇÃO DAS ATIVIDADES } \\
\hline & $\begin{array}{c}\text { OBJETIVO DO } \\
\text { ENCONTRO }\end{array}$ & PROPÓSITO \\
\hline 1 & $\begin{array}{l}\text { \$Circunscrever e definir o } \\
\text { fenômeno bullying, por meio } \\
\text { de uma atividade de } \\
\text { Modelagem, Caso } 1 . \\
\text { \$ Socializar a } \\
\text { autoavaliação do professor } \\
\text { para superação do bullying. }\end{array}$ & $\begin{array}{l}\text { Neste momento podemos compartilhar o que entendem por } \\
\text { bullying, já que nem sempre pensam o mesmo sobre os casos de } \\
\text { maltrato, como surgem, por que ocorrem, quão graves eles são } \\
\text { etc. } \\
\text { Para tanto, os professores realizarão }{ }^{5} \text { uma atividade de } \\
\text { modelagem CASO 1. } \\
\text { Como pensamos colocar em prática um projeto? } \\
\text { Por meio da questão norteadora, da atividade de modelagem, } \\
\text { os professores: }\end{array}$ \\
\hline
\end{tabular}

\footnotetext{
${ }^{5}$ Neste quadro a escrita no futuro foi mantida, pois foi este o quadro original do Planejamento da Formação, que é um dos documentos da formação, o qual apresenta a sequência do planejamento produzido pelos formadores para a realização dos encontros.
} 


\begin{tabular}{|c|c|c|}
\hline & & $\begin{array}{l}\text { - Assistirão a um vídeo sobre o tema bullying que propicie } \\
\text { perguntas e questões que podem ser retomadas para dar } \\
\text { informações; } \\
\text { - Farão leitura comentada de um caso de bullying; } \\
\text { - O que é bullying? / Como acontece? / Quais são os } \\
\text { envolvidos? / Quais as formas de maus-tratos se configuram } \\
\text { como bullying? } \\
\text { (Neste momento iremos circunscrever e definir o fenômeno, } \\
\text { por das socializações dos professores durante os } \\
\text { questionamentos da atividade de modelagem. Com a definição } \\
\text { tentamos esclarecer a que nos referimos quando falamos de } \\
\text { bullying, sua significação social, educativa e os perfis dos sujeitos } \\
\text { que participam dele: ola agressor/a, a vítima e os/as } \\
\text { espectadores/as. Indagaremos também as consequências e } \\
\text { causas que estão por trás do fenômeno, assim como as variáveis } \\
\text { de possível incidência, tanto protetoras como de risco e as } \\
\text { hierarquias presente na escola). } \\
\text { Obs.: Disponibilizar na plataforma o texto para estudo dos } \\
\text { professores (TOGNETTA, 2015). Assim também, } 2 \text { vídeos do } \\
\text { YouTube, de Tognetta acerca do fenômeno bullying: } \\
\text { videoaula } \\
\text { https://www.youtube.com/watch?v=3NKL9u11ARk } \\
\text { videoaula } 2- \\
\text { fiwoCsPXD4 } \\
\text { Em seguidas://www.youtube.com/watch?v=- disponibilizar para os/as professores/as a } \\
\text { autoavaliação (TOGNETTA, 2015) para análise de sua atuação } \\
\text { para a manutenção de ambientes cooperativos. Essa } \\
\text { autoavaliação será disponibilizada por meio da interface } \\
\text { MentimenterlGoogle Formulários. } \\
\text { Para estudo: Texto } 1 \text { (responder no chat questionamentos } \\
\text { acerca da compreensão sobre o capítulo). }\end{array}$ \\
\hline 2 & $\begin{array}{l}\text { \$Seguir com a atividade de } \\
\text { modelagem; } \\
\text { \$Analisar, por meio de } \\
\text { história, o fenômeno } \\
\text { bullying. }\end{array}$ & $\begin{array}{l}\text { Seguir com a atividade de modelagem, agora em pequenos } \\
\text { grupos de resolução: } \\
\text { - Análise da realidade da comunidade educativa, por meio } \\
\text { de modelos matemáticos para avaliação e organização de um } \\
\text { projeto. } \\
\text { (Por meio da atividade de modelagem existirão ações sobre } \\
\text { difusão, sobre indivíduos, sobre grupos e entornos, } \\
\text { acompanhamento e avaliação). } \\
\text { Para realização da atividade de modelagem, dividiremos os } \\
\text { professores em equipes de resolução, para tanto usarão ou a } \\
\text { videoconferência do WhatsApp, ou a própria videoconferência do } \\
\text { Moodle. Os formadores estarão on-line para sanar as dúvidas de todos } \\
\text { os grupos. } \\
\text { Após conclusão da atividade, cada grupo fará sua inserção } \\
\text { na plataforma em formato de arquivo de texto ou imagem (foto, } \\
\text { scanner da atividade). No próximo encontro socializarão a } \\
\text { atividade. } \\
\text { Para estudo: Texto } 2 \text { e } 3 \text { (responder no chat questionamentos } \\
\text { acerca da compreensão sobre o capítulo). } \\
\text { Análise do PPP do colégio: Como o projeto educativo da } \\
\text { escola aborda as relações interpessoais? Quais lugares ocupam } \\
\text { os temas da convivência? Que lugar ocupa o bullying? Com qual } \\
\text { abordagem se trata o maltrato: punitivo, instrumental ou } \\
\text { ecológico? }\end{array}$ \\
\hline 3 & $\begin{array}{l}\text { \$Socializar a atividade de } \\
\text { modelagem desenvolvida } \\
\text { pelos professores; }\end{array}$ & $\begin{array}{l}\text { Socialização, pelos professores, da atividade de modelagem } \\
\text { realizada por cada grupo, por meio de videoconferência. } \\
\text { Socialização da percepção da atividade relacionando-a a } \\
\text { ambientes cooperativos - leitura do texto } 5 \text { encaminhado. }\end{array}$ \\
\hline
\end{tabular}




\begin{tabular}{|c|c|c|}
\hline & $\begin{array}{l}\text { \$Analisar as percepções } \\
\text { acerca de um ambiente } \\
\text { cooperativo; } \\
\text { \$ Apresentar diferentes } \\
\text { perspectivas de modelagem } \\
\text { matemática. } \\
\text { \$Atividade de modelagem, } \\
\text { Caso } 2 \text {. }\end{array}$ & $\begin{array}{l}\text { Em seguida apresentar aos participantes as diferentes } \\
\text { perspectivas de modelagem identificadas na literatura, bem como } \\
\text { entender o que Barbosa (2007, 2009) denomina espaços de } \\
\text { interação, os quais promovem diferentes discussões entre os } \\
\text { estudantes na sala de aula. } \\
\text { Para estudo: Texto } 6 \text { e } 7 \text { (responder no chat questionamentos } \\
\text { acerca da compreensão sobre o capítulo). }\end{array}$ \\
\hline 4 & $\begin{array}{l}\text { \$Compreender a utilização } \\
\text { de ferramentas tecnológicas } \\
\text { no ambiente de modelagem } \\
\text { matemática; } \\
\text { \$Desenvolver uma } \\
\text { atividade de modelagem de } \\
\text { Caso 2, tematizando o } \\
\text { bullying. }\end{array}$ & $\begin{array}{l}\text { - Atividade de modelagem CASO } 2 \text {. } \\
\text { O propósito desse encontro será apresentar uma proposta de } \\
\text { articulação entre a modelagem e as tecnologias, discutindo } \\
\text { resultados de investigações da área. Além disso, nesse encontro, } \\
\text { os participantes terão a oportunidade de desenvolver uma } \\
\text { atividade de modelagem denominada por Barbosa (2009) de caso } \\
\text { 2, relacionada com a temática bullying. } \\
\text { Para estudo: Texto } 8 \text { (responder no chat questionamentos acerca } \\
\text { da compreensão sobre o capítulo). }\end{array}$ \\
\hline 5 & $\begin{array}{l}\text { \$Socializar a atividade de } \\
\text { modelagem desenvolvida } \\
\text { pelos professores (Caso 2); } \\
\text { \$Analisar os diferentes } \\
\text { tipos de discussões no } \\
\text { ambiente de modelagem } \\
\text { (matemáticas, técnicas e } \\
\text { reflexivas) }\end{array}$ & $\begin{array}{l}\text { O propósito desse encontro será refletir sobre os diferentes tipos } \\
\text { de discussões no ambiente de modelagem (matemáticas, } \\
\text { técnicas e reflexivas), a partir da resolução do CASO } 2 \text { dos } \\
\text { participantes, com ênfase na discussão sobre bullying. }\end{array}$ \\
\hline 6 & $\begin{array}{l}\text { \$Discutir o fazer } \\
\text { modelagem e o papel do } \\
\text { professor na sala de aula. } \\
\text { \$Apresentar diferentes } \\
\text { perspectivas de modelagem } \\
\text { matemática } \\
\text { \$Caracterizar } \\
\text { planejamento do ambiente } \\
\text { de modelagem matemática. } \\
\text { \$Propor a elaboração e } \\
\text { discussão o planejamento } \\
\text { do ambiente de modelagem } \\
\text { na sala de aula com o tema } \\
\text { bullying (CASO 1,2 ou 3). }\end{array}$ & $\begin{array}{l}\text { Esse encontro terá como meta caracterizar o planejamento do } \\
\text { ambiente de modelagem e convidar os professores a elaborarem } \\
\text { um planejamento, visando à implementação na sala de aula, a fim } \\
\text { de que tanto os professores participantes quanto o formador } \\
\text { possam contribuir no processo de construção dos planejamentos } \\
\text { de modelagem envolvendo as diferentes propostas com } \\
\text { modelagem e o tema bullying. }\end{array}$ \\
\hline 7 & $\begin{array}{l}\text { \$ Realizar atividade de } \\
\text { modelagem em sala de } \\
\text { aula. }\end{array}$ & $\begin{array}{l}\text { Realização da atividade de modelagem em sala de aula, com } \\
\text { planejamento construído pelo professor(a). }\end{array}$ \\
\hline 8 & $\begin{array}{l}\text { \$Socializar a realização da } \\
\text { atividade de modelagem em } \\
\text { sala de aula. }\end{array}$ & $\begin{array}{l}\text { O propósito desse encontro será a socialização da realização da } \\
\text { atividade de modelagem em sala de aula, pelos professores. }\end{array}$ \\
\hline
\end{tabular}

Fonte: Grupo de Pesquisa NEEMFS (Núcleo de Estudos em Educação Matemática de Feira de Santana).

Com a análise dos documentos, foi observado que, além dos encontros virtuais semanais e das atividades assíncronas, a formação foi composta por quatro lives, com a participação de profissionais convidados e temas afins aos módulos. A partir da análise dos dados, foi possível identificar como são utilizados os textos dos discursos instrucionais por meio das seguintes categorias, a saber: 1) Modelagem e a experiência no espaço remoto; 2) A modelagem para reconhecer o fenômeno bullying. 


\section{1) Modelagem e a experiência no espaço remoto}

A modelagem se configura como um ambiente de aprendizagem e para que a sua implementação em sala de aula se concretize, requer, antes de tudo, aprender a ensinar. Por meio das observações e vivências quando o professor assume papel de estudante, que de forma homóloga, a partir da interação, o professor reconhece concepções de modelagem, bem como as dificuldades que existam porventura ao se deparar com uma atividade de natureza aberta. Estes reconhecimentos se concretizam melhor ainda, se puderem se reunir com mais colegas professores.

Uma das convergências em investigações na área de Educação Matemática sobre 0 conhecimento profissional dos professores se refere à importância de os professores terem oportunidades, por meio de momentos formativos, de viver experiências matemáticas do tipo das que se espera que eles desenvolvam em sala de aula.

Concordamos com Libâneo (1996) que, para que o professor reconheça os problemas envoltos em sua formação inicial, bem como, identifique que alguns dos seus textos são insuficientes para fins pedagógicos, é necessário que as universidades estejam mais próximas, para que o discurso desse profissional se aproxime da realidade da sociedade, do conhecimento, dos estudantes, a partir de novas atitudes docentes.

É certo que o ensino, por meio de práticas pedagógicas, exige do professor a realização de diversos ambientes de aprendizagens, como a modelagem, por exemplo. Se o professor não reconhece e nem utiliza esses ambientes favoráveis à circulação de diversos textos em uma prática pedagógica, regulando e intervindo nessas produções, é muito difícil que os estudantes potencializem as produções dos seus textos. É daí que se postula uma atitude interdisciplinar que mobilize diferentes textos do discurso instrucional da matemática, da moral, por exemplo.

Como podemos observar nos encontros 1 e 2, evidenciado no quadro 2, os professores vivenciaram uma atividade de modelagem CASO 1. Nestes dois encontros, observou-se que houve a possibilidade dos professores se aproximarem do texto legítimo de que em uma atividade de modelagem, na perspectiva sociocrítica, ocorreu a reflexão sobre aspecto da realidade e que foram selecionados argumentos importantes para formalização (modelo matemático) que possibilitou que matematizassem tais argumentos.

$\mathrm{Na}$ formação houve o convite pelo formador, essencial para instigar os participantes da formação para mobilizarem as resoluções. Em seguida, por meio da interação, mediante o trabalho em grupo, os cursistas, mediado pelos formadores, a partir dos dados fornecidos pelos 
formadores, buscaram resoluções para a situação-problema, por meio da análise de dados e formulação de modelos. Em seguida, foi aberto o espaço para o compartilhamento da matematização, por meio da socialização, para que todos os grupos discorressem sobre as soluções encontradas, para validação dos modelos, se precisavam ser revistos ou não. Por fim, ocorreu a formalização, por intermédio dos modelos matemáticos já que no ponto de vista sociocrítico, é importante que os participantes produzam discussões reflexivas, mediante os modelos construídos.

A ampliação do texto se deu em relação à modelagem, já que durante a realização da atividade, os professores, em momento formativo, ampliaram os textos, não apenas sobre bullying, tema mobilizado por meio da atividade de modelagem, mas também sobre as próprias etapas que envolvem a atividade, como a importância do convite e a condução do professor. A saber:

[1]Beatriz: Como a professora tentou despertar o interesse do grupo?

[2]Yara: A professora coloca 0 aluno no processo, no centro do processo de ensino e aprendizagem. Ela dá vez e dá voz aos alunos, né?! Ela considera todas as respostas dos alunos, dando esse incentivo para que eles continuem participando, né?! Eles se sentem participantes daquele processo, porque eles estão aprendendo e como aprendiz eles precisam participar. É tão interessante a maneira como ela faz questionamentos o tempo inteiro, instigando para ouvir as respostas e a partir de cada resposta continua aquele processo com o tema que escolheu. \{Beatriz balança a cabeça, sorri, validando o texto de Yara\}

[3]Pierre: A professora vai encaminhando a aula a partir da resposta dos alunos. [...] Ela vai partir para essa discussão, que ela vai conseguir levar, inclusive, para discussão da sua disciplina específica.

[4]Beatriz: Excelente! O que mais? Qual é o padrão de comunicação presente nesse convite? O que é que caracteriza o convite? 0 convite se dá só no início, ou preciso sempre está mobilizando, potencializando, para que esse aluno participe do processo?

[5]Yara: Oh! Beatriz, continua instigando, né? Convidando para estar participando do tema.

[6]Kari: A mobilização constante.

[7]Helena: Convidar sempre. Instigar sobre 0 assunto.

[8]Pierre: Mobilizar.

[9]Beatriz: Excelente! Precisamos estar ativos, sair realmente provocando o grupo instigando, chamando aquele que está mais resistente para tentar participar, tentar conquistar esse aluno para que ele possa se envolver no processo.

Como sinalizado no excerto acima, a formadora Beatriz, em 1, instiga os professores, em formação, a socializarem de que forma o professor atua durante a atividade de modelagem para envolver os estudantes. Fica evidente, em 5, quando a professora participante passa a operar o texto legítimo sobre a condução do professor. Neste momento de interação no Google Meet, quando ela socializa e, em simultâneo, questiona à formadora, com propósito de que Beatriz, a formadora, afirme ou não a legitimidade do texto que ela estava produzindo. 
Pierre amplia seu texto e se aproxima do texto legítimo, considerado nessa formação, de que as discussões durante uma atividade de modelagem não devem ser apenas de socialização e exploração dos alunos em relação à temática, mas de considerar os modelos, quando sinaliza que a professora "vai partir para essa discussão, que ela vai conseguir levar, inclusive, para discussão da sua disciplina específica". Quando ele sinaliza "de sua disciplina específica", está relacionando aos modelos matemáticos.

No encontro 3 , os professores tiveram a oportunidade de realizar uma atividade de CASO 2, ampliando seu texto quanto aos casos que se podem desenvolver atividades, a depender do tempo, da temática. Além disso, como nos mostra os encontros 4,5 e 6 , os professores tiveram a oportunidade de desenvolver em grupos, atividades de modelagem dos três casos, compartilhar com os formadores, para retornos, ajustes, orientações.

Vivenciar uma atividade de modelagem favorece o reconhecimento do texto instrucional e mudança na prática pedagógica, além disso, favorece a percepção da importância de que circulem textos de construção coletiva, por meio da identificação de problemas mais importantes para a comunidade, temas geradores que possibilitem a produção de textos mais globalizante dessa realidade, a partir da contribuição de vários discursos.

\section{2) A modelagem como forma de reconhecer o fenômeno bullying}

A modelagem, com seu papel enviesado na sociedade, contribui não apenas para instrumentalizar os estudantes matematicamente, mas para refletir o papel da matemática na sociedade.

Utilizando da homologia dos processos e reconhecendo o docente como um autor dos processos de ensino e aprendizagem que, a partir de suas experiências, conhecimentos e contextos, elabora novas experiências e novos textos com os alunos. Esse mesmo processo ocorre na formação de professores. Para que o professor desenvolva práticas pedagógicas com diferentes ambientes e recursos, ele precisa viver isso também em sua formação. Se professores devem ensinar de maneira ativa, eles precisam aprender da mesma forma. Desenvolvimento de habilidades e competências, por exemplo, devem ser prioridade para docentes antes de serem objetos de aprendizagem dos estudantes.

Libâneo (2014) ressalta que não basta que os conteúdos sejam apenas ensinados, é importante que se conectem, de forma indissociável, à sua significação humana e social. Concordamos com ele de que esse processo ocorre em qualquer prática pedagógica, seja 
formador/ professor, seja professor/ aluno. Ainda, segundo o autor, a educação é uma atividade mediadora no seio da prática social global, ou seja, uma das mediações pela qual o estudante, pela intervenção do professor e por sua própria participação nos diferentes momentos de sala de aula, passa de uma experiência inicialmente confusa e fragmentada (do senso comum), a uma visão sintética, mais organizada (conhecimento científico/ texto legítimo). Dessa maneira, de forma homóloga, os professores vivenciaram no momento formativo uma atividade de modelagem tematizando bullying, para reconhecer o fenômeno, não pelo senso comum, mas por meio do texto legítimo do que é bullying, quais características se constituem esse fenômeno, quem e quais são os envolvidos, como fica evidenciado nos encontros 1, 2, 3, 4, 5, do quadro 2.

Inicialmente, quando os professores se referiam ao bullying o faziam por textos não legítimos sobre as caraterísticas do fenômeno, como apresentado nos excertos abaixo, retirados do questionamento realizado por meio de formulário: Já presenciou ou mediou algum caso de bullying envolvendo os seus alunos? Caso a sua resposta à pergunta anterior for sim. Qual(is)?

[10]Kari: Orientação sexual, racismo...

[11]Ana Luiza: Sempre "médio" entre os alunos questões envolvendo brincadeiras que são ofensivas. Deixando claro que se ofende o outro, não é brincadeira.

[12]Mariana: Homofobia, gordofobia.

[13]Demerval: Agressões verbais, apelidos.

[14]Cícera: Racismo.

[15]Júlia: Apelidos maldosos.

[16]Fa: Preconceito.

[17]Ana: Alunos com necessidades especiais.

[18]Jau: Crianças que são chamadas gorda, negra e cabelo feio.

[19]Jota: Gordofobia e Homofobia.

[20]Carla: Relatos de estudantes em relação à cor de pele, classe social, peso etc.

[21]Maria Rosa: Preconceito intelectual e físico.

Neste excerto observa-se que os cursistas realizam um texto sobre situações de bullying vivenciadas. Quando os participantes se referem à ocorrência de bullying por conta de orientação sexual, racismo, brincadeiras ofensivas, homofobia, gordofobia e preconceito, tornaram visíveis, naquele momento inicial, os textos que os participantes reconheciam e realizavam acerca do fenômeno. Estes textos são legítimos ao se tratar de problemas de convivência nas escolas, como sinaliza Tognetta (2020), porém em relação ao bullying, com toda a sua complexidade, não se configura como texto legítimo, já que nem toda brincadeira é bullying, nem todo gordo, homossexual sofrem bullying (TOGNETTA, 2017, 2020; CROCHICK; CROCHICK, 2017). Além disso, o preconceito é uma forma de expressão da violência e há uma distinção em relação ao bullying, já que o alvo do bullying é qualquer um que seja fragilizado moralmente e que possa ser 
submetido; "0 preconceito, em geral, necessita de uma justificativa para a discriminação" (CROCHICK; CROCHICK, 2017, p. 28).

O reconhecimento do fenômeno bullying se deu por meio das produções dos textos que se tornaram públicos, isto é, se tornaram visíveis (BERNSTEIN, 1996). Em um dos momentos de interação no chat, no Google Classroom, sobre Capítulo 1 - Livro "Bullying: quem tem medo?" (TOGNETTA, 2015), foi possível observar, que ao produzir o texto legítimo os cursistas explicitavam a ampliação dos textos, e o reconhecimento do texto legítimo sobre bullying, segundo as referências socializadas nos encontros, tornando evidente a produção de significados pertinentes a bullying.

[22]Pierre: O Bullying é um ato de violência (maus-tratos) constante entre iguais. É comum que haja além do autor do Bullying a plateia ou cúmplices e essa violência se configura como um ato de exclusão social, visto que as práticas repetitivas de violência (Bullying) acabam por afastar/isolar o agredido daquele meio. Destaco que as violências cometidas entre: alunos $\mathrm{x}$ professores ou professores $\mathrm{x}$ alunos não se configuram como Bullying visto que, eles não têm o mesmo "poder instituído", ou seja, não estão entre pares. As violências que acontecem de forma "estanque" também não se configuram com bullying.

[23]Kari: 0 bullying se caracteriza por ser um fenômeno em destaque nas escolas, nas relações em que há violência entre crianças, adolescentes ou adultos que tenham o mesmo "poder instituído" de agir, portanto, não tenham diferenças quanto à autoridade. Por ser uma forma de violência, seja ela verbal, física ou psicológica, o bullying pode ser confundido com outras manifestações de violência, dessa forma, existem características que o diferenciam, tais como: ações agressivas que ocorrem repetitivas vezes, intencionais e que ocorrem entre pares, ou seja, há sempre um autor e uma vítima, esta, por sua vez, é escolhida por ser um alvo frágil para ser agredido, ofendido e maltratado. Sempre acontecendo diante de um público, que se mostra indiferente a tudo que presencia. É válido ressaltar que outros tipos de violência, sejam elas de cunho racial, religioso, econômico, sociocultural, sexual, entre outros, podem ocorrer no ambiente escolar ou fora deste, mas que possuem características isoladas, não agrupando simultaneamente todas essas características que traduzem o termo "bullying".

[24]Ana Luiza: Bullying é o ato de violência contra o igual de forma repetitiva e observada. É o uso da intimidação, humilhação e agressão contra o colega, na justificativa de se sentir superior ao mesmo. Não há bullying quando a violência ocorre com pessoas de níveis diferentes. Quando são casos isolados de violência, ou quando não é alimentado pelos espectadores.

Jau: 0 bullying é quando as ações agressivas são intencionais e repetitivas. 0 autor escolhe alguém frágil para agredir e ofender diante de um público. Não é considerado bullying quando a ação de violência é feita por pessoas de diferentes níveis. Ex.: professor - aluno.

Por fim, nos excertos 22, 23 e 24, é possível observar que os participantes produziram textos que demonstram reconhecer as características do bullying e circunscrevem o fenômeno. Além disso, após vivenciarem toda a experiência no espaço formativo, de forma homóloga, desenvolveram a atividade de modelagem com os estudantes e socializaram os resultados com os formadores. 
Alguns estudiosos sobre a temática de violência, bullying, indisciplina e suas implicações no desenvolvimento de aprendizagem dos estudantes, como Tognetta e Vinha (2009); Tognetta (2015); Díaz-Aguado (2015); Crochick e Crochick (2017), entre outros, ressaltam que o problema de violência na escola se apresenta como um problema grave, necessitando de uma atenção especial do contexto escolar e dos profissionais que atuam neste contexto, o que evidencia a importância desta tematização no ambiente de modelagem.

\section{Conclusão}

Esta pesquisa teve como propósito identificar os textos do discurso instrucional de modelagem matemática, tematizando o bullying, dos materiais planejados pelos formadores, que foram operados na relação pedagógica entre formadores e professores da educação básica, que participaram de uma formação e-learning. Com isso, na formação colaborativa, foi possível entender melhor como os textos dos atores, neste caso dos envolvidos no espaço formativo, formadores e professores participantes da formação, se transformam, por meio de conhecimentos que se agregam, novos textos que interagem entre si, partindo da interação dos sujeitos no ambiente de formação e de elementos de uma prática colaborativa.

Por meio da categoria Modelagem e a experiência no espaço remoto, foi possível identificar a importância da adaptação do processo de aprendizagem aos meios tecnológicos disponíveis. Além disso, a contribuição do e-learning para se desenvolver ambientes de aprendizagem, pela possibilidade de exploração de diversas on-lines disponíveis na Internet, na partilha de experiências entre todos os participantes independentemente da sua localização geográfica, na partilha de saberes e de aprendizagem no espaço virtual, se constituindo como uma forma viável de ampliação das aprendizagens. A modelagem se configura como um ambiente de aprendizagem e para que a sua implementação em sala de aula se concretize, requer, antes de tudo, que o professor estabeleça diferentes relações com a atividade de modelagem, as possíveis dificuldades para serem sanadas nas trocas entre pares.

Assim também, a categoria A modelagem como forma de reconhecer o fenômeno bullying possibilitou que professores reconhecessem que a modelagem, por ser uma atividade aberta com natureza interdisciplinar, gera um ambiente propício para a expressão de diferentes opiniões, sentimentos, no que se refere a um determinado tema, oportunizando-os, às discussões do fenômeno bullying e suas implicações no ambiente escolar, por meio da matematização de dados 
e investigações acerca da sua progressão caso não se mobilizem espaços cooperativos e que tematizem sobre os problemas de violência na escola.

Este é o aspecto mais importante quando se abrem espaços colaborativos de formação - a transformação dos textos dos sujeitos envolvidos; já que o que é reconhecido e como se aborda a modelagem tematizando o bullying são transformados em um novo texto legítimo desses ambientes (o que e como se aborda modelagem tematizando bullying em sala de aula).

Face ao exposto, é possível abrir um leque de discussões em outras dimensões a respeito deste fenômeno, que é de extrema relevância no ambiente escolar, para contribuir no processo de combate à violência na escola.

\section{Referências}

AVILÉS, J. M. M. Bullying: guia para educadores. Tradução J. Guillermo Milá-Ramos: revisão técnica Luciene Regina Paulino Tognetta. Campinas: Mercado de Letras, 2013.

AVILÉS, J. M. M. Os sistemas de apoio entre iguais na escola: das equipes de ajuda à cybermentoria. Tradução Vinícius Pessoa. Americana: Adonis, 2018.

BARBOSA, J. C. Modelagem Matemática: concepções e experiências de futuros professores. 253 f. Tese (Doutorado em Educação Matemática) - Instituto de Geociências e Ciências Exatas, Universidade Estadual Paulista, Rio Claro, 2001.

BARBOSA, J. C. What is Mathematical Modelling? In: LAMON, S. J.; PARKER W. A. e HOUSTON, K. (eds.). Mathematical Modelling: a way of life. Chichester, Ellis Horwood, 2003.

BARBOSA, J. C. Teacher-student interactions in mathematical modeling. In: HAINES, C.; GALBRAITH, P.; BLUM, W. e KHAN, S. (eds.). Mathematical Modelling: Education, engineering and economics. Chichester, Horwood. 2006a.

BARBOSA, J. C. Mathematical modelling in the classroom: socio-critical and discursive perspective. Zentralblatt für Didaktik der Mathematik, v. 38, p. 293-301. 2006 b.

BARBOSA, J. C. Integrando Modelagem Matemática nas práticas pedagógica. Educação Matemática em Revista, São Paulo, v. 26, p. 17-25, 2009.

BERNSTEIN, B. Pedagogy, symbolic control and identity: theory research Critique. Revised Edition. London: Taylor and Francis, 2000.

BERNSTEIN, B. Pedagogía, control simbólico e identidad: teorias, investigacíon y crítica. Por Basil Bernstein; traduccuión de Pablo Manzano; revisión de Basil Bernstein, Juia Varela. São Paulo: Cortez; Madrid, España: Ediciones Morata, 2017.

BOGDAN, R. C; BIKLEN. S. K. Investigação qualitativa em educação: uma introdução à teoria e aos métodos. Portugal: Porto LDA, 2003. 
BORTOLOTI, R. D'A. M. PEROVANO. A. P. Produção de textos matemáticos: a comunicação entre professor e crianças. Educação Matemática Debate, Montes Claros, v. 2, n. 6, set./dez. 2018.

BOSE, K. An e-learning experience: A written analysis based on my experience in an e-learning pilot project. Campus-Wide Information System, n. 5, v. 20, 2003.

CIVIERO, P.A.G. Educação Matemática Crítica e as implicações sociais da Ciência e da Tecnologia no Processo Civilizatório Contemporâneo: embates para Formação de Professores de Matemática. 2016. 382 f. Tese (Doutorado) - Programa de Pós-Graduação em Educação Científica e Tecnológica, Universidade Federal de Santa Catarina, Florianópolis, 2016.

CROCHÍK, J. L; CROCHICK, N. Bullying, preconceito e desempenho escolar: uma nova perspectiva. São Paulo: Benjamin Editorial, 2017.

DÍAZ-AGUADO; M. J. Da violência à cooperação na sala de aula. Americana: Adonis, 2015.

FREITAS, A. S. A implementação do e-learning nas escolas de gestão: um modelo integrado para o processo de alinhamento ambiental. Tese (Doutorado em Administração) Pontifícia Universidade Católica do Rio de Janeiro, Rio de Janeiro, 2009.

LIBÂNEO, J C. Democratização da escola pública: a pedagogia crítico-social dos conteúdos. 28.ed. Coleção Educar. Edições Loyola. São Paulo, 2014.

LIMA, L. B. S.; LUNA, A. V. A. Os textos referentes às concepções de modelagem matemática que circulam em um curso de formação inicial. XI CNMEM - Conferência Nacional sobre Modelagem na Educação Matemática Modelagem Matemática na Educação Matemática e a Escola Brasileira: atualidades e perspectivas. Anais... UFMG: Belo Horizonte, MG - 14 a 16 de novembro de 2019. ISSN: 2176-0489

LÜDKE, M.; ANDRÉ, M. E. D. A. Pesquisa em educação: abordagens qualitativas. São Paulo: EPU, 1986.

NICHOLS, M. E. Primer Series - E-learning in context. Laidlaw College, New Zealand, 2008.

PULTOO, A. OOJORAH, A. Designing remote education in a VUCA world. International Journal of Computers and Technolog, v.20, 2020.

SKOVSMOSE, O. Desafios da Educação Matemática Crítica. São Paulo: Papirus, 2008.

TOGNETTA. L. R. P. Até quando? Bullying na escola que prega a inclusão social. Educação, Santa Maria, v. 35, n. 3, p. 449-464, 2010.

TOGNETTA, L. R. P. Bullying: quem tem medo? uma proposta de implementação de um programa em que a convivência entre as crianças na escola seja um valor. Americana: Adonis, 2015.

TOGNETTA, L. R. P.; VINHA, T. P. Construindo a autonomia moral na escola: os conflitos interpessoais e a aprendizagem dos valores. Revista Diálogo Educacional, Curitiba, v. 9, n. 28, p. 525-540, 2009. 
TOGNETTA, L.R. P. VINHA, T. P.; AVILÉS, J. M. M. Bullying e a negação da convivência ética: quando a violência é um valor. International Journal of Developmental and Educational

Psychology INFAD Revista de Psicología, n. 1, v. 7, 2014. ISSN: 0214-9877. p. 315-322, 2014. 